\title{
O uso de uma interface conversacional como ferramenta de interação em um ERP para indústria da construção
}

\author{
Jefferson Alex Bezerra da Silva Rozendo \\ Universidade Federal de Pernambuco \\ Caruaru Pernambuco Brasil \\ jefferson.alex.silva@gmail.com
}

\section{RESUMO}

Dentre os muitos desafios encontrados no desenvolvimento e utilização dos ERPs ${ }^{1}[1]$, estão a forma com que os dados são apresentados em tela e como são analisados pelos usuários. Considerando a necessidade de uma alta carga cognitiva para compreensão essas informações complexas apresentadas em tela, busca-se outros meios para auxiliar o usuário na utilização do sistema e consequentemente, a eliminação dessas barreiras. Este trabalho apresenta a implementação de processamento de linguagem natural [2] (PLN), por meio de bot, em um ERP utilizado na construção civil. O processo explora o design centrado no usuário, realizado em 2 fases (entrevistas qualitativas e validação de hipóteses quantitativamente), identificando pontos que auxiliam o usuário na tomada de decisão sobre a gestão financeira da sua construtora. Essa exploração resultou em um fluxo de conversação com duas abordagens, denominadas pelos autores de passiva e proativa, via chatbot, integrado com a interface gráfica do ERP. O fluxo de conversação permite a visualização de informações em formato reduzido e estratégico, aplicando filtros que eliminam a necessidade de relatórios detalhados para a tomada de decisão.

\section{PALAVRAS-CHAVE}

Processamento de linguagem natural, chatbot, enterprise resource planning

\section{INTRODUÇÃO}

Um dos desafios encontrados no desenvolvimento de sistemas complexos, como os sistemas de gestão integrada (ERPs) é o engajamento do usuário e a demonstração de resultados decorrente do uso. Esses resultados são obtidos por meio de consolidação de relatórios, aplicação de filtros e cadastros de dados em formulários estruturados. Nesse sentido, a geração de

Permission to reproduce or distribute, in whole or in part, material extracted from this work, verbatim, adapted or remixed, as well as the creation or production from the content of such work, is granted without fee for non-commercial use, provided that the original work is properly credited.

IHC 2019 - TRILHA PÔSTERES E DEMONSTRAÇÕES, Outubro 21-25, 2019, Vitória, Brasil. In Anais Estendidos do XVIII Simpósio Brasileiro sobre Fatores Humanos em Sistemas Computacionais. Porto Alegre: SBC.

(C) 2019 by the author(s), in accordance with the terms of the Creative Commons Attribution-NonCommercial 4.0 International Public License (CC BY-NC 4.0).

1 Enterprise Resource Planning: Sistema Integrado de Gestão Empresarial.

\author{
Karen Schmidt Lotthammer \\ Universidade Federal de Santa Catarina \\ Araranguá Santa Catarina Brasil \\ lotthammer_karen@hotmail.com
}

relatórios tem se mostrado um senso comum entre as equipes de desenvolvimento de sistemas, pois é um formato conhecido de obtenção de informações em um sistema ERP.

A interpretação de informações geradas por sistemas de gestão necessita de uma carga de conhecimento prévia, onde o usuário é o responsável pela busca desses dados e, em muitos casos, modelagem deles para consolidação e entendimento da informação gerada.

Analisando esse cenário de interação humano-sistema e dados, surge-se a necessidade de gerar mecanismos para diminuir a carga cognitiva desses usuários, tornando facilitada a análise dos dados em um ERP. Pois assim,, aproxima-se a informação do seu entendimento natural, possibilitando a tomada de decisão mais ágil e deixando que o gestor tenha foco no processo e não na ferramenta.

Algumas alternativas para esse desafio relatado são a utilização de gráficos e mensagens de notificação. Esta última alternativa pode ser explorada como forma de interação por meio da linguagem natural, entregando mais facilmente as informações do sistema ao usuário.

Este trabalho possui como objetivo apresentar a utilização de processamento de linguagem natural (PLN), por meio de agentes virtuais (bots), como ferramenta de apoio ao uso de um software de gestão da indústria da construção civil. Para isso, pretende-se responder a seguinte pergunta: como uma interface conversacional pode auxiliar na interpretação de dados em um ERP?

Com este propósito, é apresentado a seguir a pesquisa desenvolvida para identificação e elaboração das interações com o sistema.

\section{METODOLOGIA}

O sistema utilizado como base para este estudo de caso se trata de um ERP, especializado em gestão de construção civil, em que os autores estão alocados no time que o desenvolveu até a publicação desse trabalho, possuindo assim acesso ao processo de desenvolvimento do projeto no qual são responsáveis pelas definições do design e interação [3].

A partir de uma investigação de cenário e necessidades reais, utilizou-se as seguintes técnicas de design centrado no usuário (DCU [4]): entrevista em profundidade, observação de cenário, prototipação e validação. Com o uso dessas técnicas buscou-se facilitar a utilização do sistema pelo usuário e diminuir a 
necessidade de interação com a interface, e ainda assim entregar a informação que o usuário necessita para o controle e tomada de decisão em sua gestão.

Foram recrutados cerca de 180 donos de construtoras de micro e pequeno porte advindos de uma campanha de marketing ${ }^{2}$, em diversas cidades do Brasil, por meio de convite eletrônico ${ }^{3}$, para participar de sessões de entrevistas. As entrevistas possuíam como objetivo principal identificar as necessidades de informação para gestão das obras. Os participantes possuem conhecimento técnico formal sobre gestão de obras, mas com conhecimento empírico em gestão financeira de suas empresas.

Na fase atual do projeto o time concentrou esforços em atender as necessidades de informação no módulo financeiro do sistema estudado.

O processo de pesquisa foi dividido em 2 (duas) etapas: 1) entrevistas qualitativas: identificação de hipóteses de frequência [5] e 2) quantitativa: validação das hipóteses levantadas por meio de formulário eletrônico estruturado. A primeira etapa foi realizada com 5 participantes [6] aleatoriamente selecionados, seguida da segunda fase com uma média de $60^{4}$ respostas válidas. Contou-se também com um mapeamento de jornada realizado por um antropólogo que identificou situações cotidianas e culturais de 4 usuários-participantes em suas respectivas empresas.

As entrevistas qualitativas foram realizadas por meio de videoconferências, com a participação dos autores, guiadas por um questionário semiestruturado onde haviam perguntas como "quais os momentos que se comunica com o escritório" e "que tipo de pergunta é feita para um assistente via aplicativo de mensagens ou ligação”. As respostas foram agrupadas de modo a associá-las aos módulos/funcionalidades existentes do ERP (em formato de mapa mental), e à jornada deste usuário, associando quais seriam os gatilhos proativos e reativos de interação.

A partir dos passos acima, chegou-se em 4 (quatro) mensagem proativas e 10 (dez) reativas implementadas na interface conversacional. Essas mensagens sintetizam relatórios para minimizar o uso da interface e maximizar o valor de inserir os dados corretamente.

A figura 1 exemplifica uma conversação onde o bot interage com a interface, gerando filtros para entendimento da informação pelo usuário.

2 As campanhas de marketing são realizadas pela empresa responsável pelo ERP para atrair gestores de construção civil de todos os portes, em várias regiões do Brasil.

3 E -mail e WhatsApp

4 Todo os recrutados receberam a pesquisa quantitativa, mesmo os que realizaram as entrevistas iniciais.

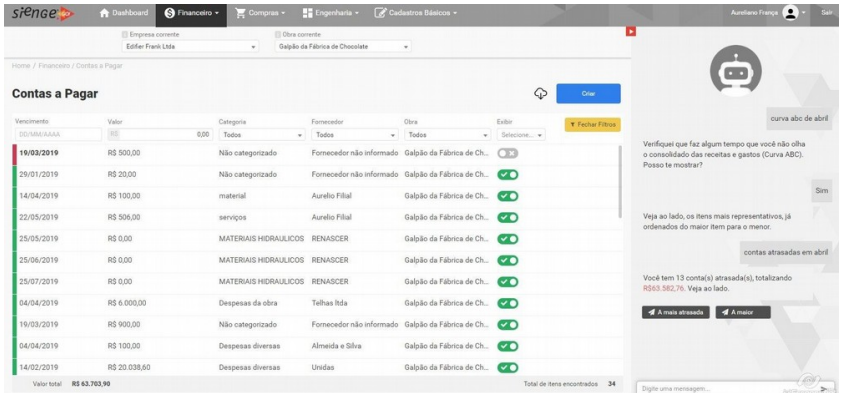

Figura 1: Captura de tela do ERP, com o bot filtrando as contas a pagar do usuário.

Após a implementação, o sistema foi liberado, em janeiro de 2019, para uso por 14 usuários, sendo 4 participantes da pesquisa inicial e 10 clientes da empresa desenvolvedora. Esses usuários foram acompanhados por meio de reunião semanal de implantação, onde foi possível questionar aos usuários sobre a interação com o bot e suas percepções acerca da sua relevância.

\section{CONCLUSÃO}

Após o ciclo de 4 semanas de acompanhamento, foi identificado um engajamento dos usuários com a interface conversacional que substituiu, por vezes, os filtros existentes no sistema por perguntas como "vai faltar dinheiro esse mês?" e "quais as contas atrasadas?”. As interações do bot, durante o registro de informações, se mostraram úteis pela contextualização e aproveitamento da interação para informações que ajudam na gestão da empresa do usuário.

Para continuidade do trabalho é necessário realizar uma curadoria de conteúdo, identificação de novos fluxos de conversa. O trabalho inicial foi realizado entre junho e dezembro de 2018. Porém, foi possível acompanhar as interações iniciais dos primeiros usuários e suas impressões.

O uso de bots para responder questões específicas em sistemas de gestão é muito embrionário, necessitando de melhores métodos de monitoramento e estratégia de curadoria que permita a escalabilidade e replicação em sistemas semelhantes.

\section{REFERÊNCIAS}

[1] R Zwicker e S Cesar Alexandre. 2008, SISTEMAS ERP: CONCEITUAÇÃO, CICLO DE VIDA E ESTUDOS DE CASOS COMPARADOS, Sistemas ERP no Brasil: (Enterprise REsource Planning) - 1. ed. - 3. Impr. - Atlas, São Paulo, SP, Brasil, $63-87$

[2] IBM. Entendendo a Liguagem Natural do Watson, https://www.ibm.com/br-pt/cloud/watson-natural-language-understanding .

[3] Sienge Go! ERP 100\% cognitivo para micro e pequenos construtores, https://www.siengego.com.br .

[4] Lowdermilk, Travis. 2013, Design Centrado no Usuário: um guia para o desenvolvimento de aplicativos amigáveis. Novatec Editora, São Paulo, SP Brasil.

[5] Gil, Antonio Carlos. 2008, Métodos e técnicas de pesquisa social - 6. ed. Atlas, São Paulo, SP, Brasil.

[6] Nielsen, Jacob. Why You Only Need to Test with 5 Users. https://www.nngroup.com/articles/why-you-only-need-to-test-with-5-users . 